\title{
Effect of Implementing Clinical Pathway Guidelines on Patients' Clinical Outcomes with Acute Coronary Syndrome
}

\author{
Safaa Eid Sayed Ahmed ${ }^{1}$, Nagwaa Ibrahim Abbas ${ }^{1}$, Sameh Samir Khalil ${ }^{2}$ \\ ${ }^{1}$ Faculty of Nursing, Tanta University, Tanta, Egypt \\ ${ }^{2}$ Faculty of Medicine, Tanta University, Tanta, Egypt
}

Email address:

a_dr_safaa@hotmail.com (S. E. S. Ahmed)

\section{To cite this article:}

Safaa Eid Sayed Ahmed, Nagwaa Ibrahim Abbas, Sameh Samir Khalil. Effect of Implementing Clinical Pathway Guidelines on Clinical Outcomes of Patients with Acute Coronary Syndrome. American Journal of Nursing Science. Vol. 6, No. 5, 2017, pp. 401-417. doi: 10.11648/j.ajns.20170605.15

Received: August 8, 2017; Accepted: September 6, 2017; Published: September 29, 2017

\begin{abstract}
Acute coronary syndrome refers to a range of potentially life-threatening conditions that affect the coronary artery blood supply to the heart. It is associated with increased patient mortality, length of hospital stay and health care costs. Clinical pathways are now one of the main tools that used to manage the quality in healthcare concerning the standardization of care processes. Hence, the aim of this study is to evaluate the effect of implementing a clinical pathway guideline on the clinical outcomes of patients with acute coronary syndrome. A quasi experimental research design was utilized in this study and it was conducted on 60 adult patients at the Cardiac Intensive Care Unit of Tanta University Hospital. The patients were divided into two groups (control and study group) 30 patients in each. The control group: non-clinical pathway group involved patients receiving the routine management regimen while the study group: clinical pathway group ( $\mathrm{CP}$ group) involved patients who received management according to the clinical pathway guidelines. The findings of this study revealed that a significant changes among control and study group from admission to discharge regarding mean scores of body temperature, Pulse and respiration rate where $\mathrm{P}<0.05$. There was significant increased mean score of central venous pressure among control group compared to study group on admission, after $2 \mathrm{hrs}$ and on $2^{\text {nd }}$ day of admission with $\mathrm{P}=0.013,0.007$ and 0.001 , respectively. The present study showed that low percentages $(20.0 \%)$ of control group had cardiogenic shock compared to none patient in the study group with a significant difference between two groups, where $\mathrm{P}=0.012$. Insignificant difference was observed between control and study group regarding duration of stay in ICU and status of patients on discharge with $\mathrm{P}=0.075$ and 0.206 . Also it was noticed that the level of reduction of the mean of Hamilton Anxiety Score in the study group was higher than its level in the control group on discharge. It can be concluded that the established pathway achieved its goal of, improving physiological parameters and decreasing patient's complications, length of stay, and anxiety levels. Based on the findings of this study, the following recommendations are suggested; clinical pathway should be implemented routinely for patients with acute coronary syndrome. Integrating ACS clinical pathway into plan of care to replace the traditional nursing care plan.
\end{abstract}

Keywords: ACS, Clinical Pathway (CP), Clinical Outcome

\section{Introduction}

Acute coronary syndrome (ACS) is the most common causes of admission to coronary care unit (CCU) and this admission is associated with a high mortality rate $[1,2]$. Acute coronary syndrome including a range of potentially life-threatening conditions that affect the coronary arteries that supply blood to the heart. It includes unstable angina
(UA), non-ST segment elevation myocardial infarction (NSTEMI) and ST segment elevation myocardial infarction (STEMI) [3]. The American Heart Association has recently revealed that 15.5 million persons who had age more than 20 years in the USA have coronary artery diseases $[4,5]$. About 2.5 million of unstable angina and myocardial infarction 
patients had hospital admissions annually worldwide [6, 7]. Cardiovascular disease resulting in death in Egypt and worldwide, placing high strain on the world's health systems. Acute Coronary Syndrome occurring in $75 \%$ of patients dying of an acute myocardial infarction $[8,9]$.

Acute Coronary Syndrome (ACS) including signs and symptoms compatible with acute myocardial ischemia which include chest pain, dyspnea, severe sweating, epigastric discomfort, diaphoresis, nausea, fatigue and syncope. Atypical symptoms of ACS may occur in certain populations such as elderly, women, diabetics and postoperatively. In these conditions, ACS may be associated with palpitations, cardiac arrest, or with an asymptomatic clinical presentation [10]. The aim of treatment of ACS is to relieve symptoms, improve coronary artery blood flow and prevent complications. Immediate management, combined with cardiac rehabilitation, secondary prevention and timely management can improve patients' outcomes, quality of life and reduce the risk of mortality and further cardiac events $[3,5]$.

The priorities of management of patients with ACS are hemodynamic monitoring and close observation of vital signs. A monitoring of fluid status provide information about renal perfusion, as some patients may present with or develop heart failure. Recognition of any cardiac abnormalities on the serial ECGs is also a key aspect of nursing care [3, 7]. Patients with ACS may be high risk for arrhythmias so they need for continuous cardiac monitoring as arrhythmias lead to cardiac arrest. Also ACS Patients are likely to be anxious and frightened therefore they need psychosocial support. Additionally, patients on discharge need to understand their condition and be encouraged to make any lifestyle changes needed, which will be crucial to prevent recurrence. So discharge plan is important to be considered [3].

Nowadays, clinical pathways are used to manage the quality of care in healthcare concerning the standardization and organization of care processes of patients with ACS. Implementation of clinical pathways reduces the variability in clinical practice and improves clinical outcomes in acute care [8]. Effective treatment of acute coronary syndrome (ACS) requires a highly functioning health care delivery system, driven by valid, reliable measurement for continuous improvement $[8,11]$. The use of clinical pathways is becoming more imbedded in the daily practice of health care and support the implementations of clinical guidelines into practice $[12,13]$.

Clinical pathways integrate nursing care plans, medical treatment, and the other care allied to healthcare professionals into a single care plan, which clearly defines the expected progress and outcomes of a patient through the hospital system [12]. It support the management processes including clinical and non-clinical activities, resources and also financial aspects. It provides detailed guidance for each stage in the management of a patient with the aim of improving the continuity and coordination of care by using a multidisciplinary team [14]. Clinical pathways aim to link evidence to practice and, therefore, optimize patient's clinical outcomes and maximize clinical efficiency of care [15].

Physicians use clinical pathways to give appropriate instructions on a daily basis. The nurses review the orders and confirm their accomplishment. Other care team members such as the therapist, nutritionist, interns and clerks carry out all the orders in the pathway pertaining to them [14]. The clinical pathway for hospitalized patients with ACS is poorly established in Tanta University, although it is an integral part of total quality management. The positive outcome of clinical pathway reported in the literature is decreased length of stay (LOS), improve hemodynamic parameters and prevent complications [14-16]. Therefore the aim of this study is to evaluate the effect of implementing clinical pathway guidelines on the clinical outcomes of patients with acute coronary syndrome.

Significance of the study:

Clinical pathways are particularly relevant to cardiovascular diseases because of the high prevalence of disease and the high costs associated with acute management. Clinical pathways are now one of the main tools used to manage the quality in healthcare concerning the standardization and organization of care processes. It has been shown that their implementation reduces the variability in clinical practice and improves outcomes in acute care.

\section{Patients and Method}

\subsection{Aim of the Study}

The aim of the study was to evaluate the effect of implementing clinical pathway guidelines on the clinical outcomes of patients with acute coronary syndrome

\subsection{Study Design}

A quasi experimental research design was utilized in this study to evaluate the effect of implementing clinical pathway on the clinical outcomes of patients with acute coronary syndrome.

\subsection{Hypothesis}

H1) patients with acute coronary syndrome who are managed by clinical pathway guidelines will have improved physiological and psychological parameters than patients managed by routine care.

H2) the frequency of post-acute coronary syndrome complications among patients in study group will be lower than patients in the control group.

H3) patients who are managed by clinical pathway guidelines will have short hospital stay \& less mortality rate than those who will not.

\subsection{Setting}

This study was conducted in Cardiac Intensive Care Unit at Tanta University Hospital 


\subsection{Subjects}

A convenience sample of sixty adult patients of both sexes (aged 40 years and above) and newly admitted to cardiac intensive care unit were included in this study and hospitalized for at least 72 hours. Primary diagnosis of patients was acute coronary syndrome which included patients with ST-segment elevation infarct (STEMI), nonST-segment elevation infarct (NSTEMI) and unstable angina. Patients were excluded from the study if they had significant co-morbidity disease as patients with advanced liver diseases, malignancy and cardiogenic shock upon admission to cardiac intensive care unit. The patients were divided into two groups (control and study group) 30 patients in each. The control group received the routine care whiles the study group received management according to the developed clinical pathway from admission until discharge.

The sample size calculation was based on the total patient's population admitted to cardiac intensive care unit annually and it was about 300 patients admitted to Cardiac Intensive Care Unit. The sample size was 60 patients.

\subsection{Ethical Consideration}

An official permission to conduct the study was obtained from directors of cardiac intensive Care Unit. Verbal consents were obtained from patients to be included in the study after explanation of the purpose of the study. Each patient has the right to withdraw from the study at any time without any rational. Confidentiality of each patient was assured through coding of all data.

\subsection{Tools}

Two tools were used to collect data about the study subjects.

Tool I: Biosocial-demographic and clinical data sheet: It was developed by the researchers and consisted of two parts:

Part (a): Biosocial-demographic data which includes patient's code, age, sex, marital status, and level of education, as well as length of hospital stay and status of patients on discharge.

Part (b): Medical clinical data such as diagnosis, past medical history\& comorbidities (such as hypertension, diabetes mellitus, COPD, cardiomyopathy, rheumatoid, MI, $\mathrm{LVH}$, and ischemic stroke smoking history and hyperlipidemia, family history of ACS. The laboratory investigation of patients include electrolytes and blood glucose level, lipid profile, troponin level and cardiac enzymes.

Tool II: acute coronary syndrome patients' outcome sheet, it involved 3 parts:

Part (a): Assessment of patient's physiological Parameters $[3,11,17]$, it was developed by the researchers after reviewing literature and covered vital signs, MAP, CVP, $\mathrm{O}_{2}$ saturation, cardiac sounds, respiratory sounds, arterial blood gases, and chest pain on admission, then after $2 \mathrm{hrs}, 2^{\text {nd }}$ day of admission and day of discharge. Assessment of intake and output on first day of admission, $2^{\text {nd }}$ day, $3^{\text {rd }}$ day, and on discharge.

Part (b): Assessment of acute coronary syndrome complications $[3,12]$, it was developed by the researchers after reviewing literature and covered complication that occurred during patient hospitalization such as cardiogenic shock, pulmonary edema, heart failure, arrhythmia, and bleeding.

Part (c): Hamilton Anxiety Scale [19], this scale was developed by Hamilton and used to assess the severity of a patient's anxiety. It consisted of 14 items; each item contains a number of symptoms and is rated on a scale of 0 (not present) to 4 (severe).

Scoring system

Total score range from $0-56$ and subcategorized as the following; total score less than 17 indicated mild severity, total score range from 18-24 indicated mild to moderate severity and total score range from 25-30 indicated moderate to severe.

Tool III: Clinical Pathway Audit Tool [18, 19]. It was developed by the researchers, and clinical pathway teams after reviewing literature to assess the point of view of 10 clinical and academic experts regarding developed acute coronary syndrome clinical pathway guidelines final draft before implementing it on patients. It consisted of 11 items. Each item is rated as "agree" and "disagree".

\subsection{Validity and Reliability of the Tool}

The tools were reviewed by five jury experts in the field of critical care nursing, medical surgical nursing, and cardiac intensive care medicine for revision of its content validity and clarity.

The reliability of the tools of physiological parameters estimated using Cronbach's Coefficient alpha test and was greater than 0.88 . The internal consistency reliability of the Hamilton Anxiety tool was greater than 0.85 .

\subsection{Procedure}

The study was carried out on four phases: assessment phase, designed ACS clinical pathway phase, implementation phase and evaluation phase.

\subsubsection{Assessment Phase}

This phase was concerned with constructing and testing data collection tools. Patient's socio-demographic and medical data were documented by the researcher in tool I for two groups. The researcher assessed clinical outcomes for two groups from the time of enrollment in the study until discharge by tool II. The clinical outcomes were measured by assessment of physiological parameters, length of ICU stay, status of patient on discharge and anxiety level. A pilot study was carried out on 6 patients who met the inclusions criteria to assess the feasibility and the applicability of the data collection tools. Based on the results of the pilot study, modifications were done.

\subsubsection{Designed Phase}

This phase was concerned with ACS clinical pathway 
development and covered the following steps:

1. The initial step involved the formation of a multidisciplinary group to review the current practice patterns and to identify any areas where improvement may have been necessary. This team consisted of at least one member from each of the various clinical services including two cardiologists from faculty of medicine, professor in faculty of nursing have extensive expertise in development and implementation of clinical pathways, two critical care nursing lecturer researcher, one pharmacist, one physiotherapist, one dietitian, the CCU head nurse and one staff nurses in CCU. At the beginning of the process, major areas of interest were studied independently in an attempt to isolate areas where the greatest fluctuation or variation existed.

2. Literature review focused on the main concepts appearing in title or major subject heading was conducted on key resources from Egyptian knowledge bank, relevant nursing and medical Journals and books, was conducted by the main researchers and CP team to identify all available evidence of clinical pathway for management of patients with ACS.

3. The expert panel and researchers met two times over a two weeks period before making the final format of clinical pathway. Each department or specialty was then asked to approve the final version of the CP. In an attempt to ensure the continued participation of all of the specialties, the group continued meeting on a regular basis to review the progress of the $\mathrm{CP}$ and to make any necessary modifications to the plan. A pilot study was carried out to evaluate the feasibility of the ACS clinical pathway and to modify the pathway accordingly. Three educational sessions about ACS clinical pathway guidelines were given for 5 nurses over three weeks to explain the clinical pathway and the nurse's roles in each stage. The ACS clinical pathway formulated into four days until patient discharges from the first 2 hours on admission, after 2 hours then $2^{\text {nd }}$ day, $3^{\text {rd }}$ day and $4^{\text {th }}$ day and the fourth day may be repeated if patient is still in ICU.

\subsubsection{Implementation Phase}

This phase was concerned with implementation of acute coronary syndrome clinical pathway guidelines. During this phase, the developed clinical pathway was applied to the study group (CP group) for 4 days. A multidisciplinary team helps in the implementation of clinical pathway for the study group. Patients admitted to the cardiac intensive care unit with a diagnosis of ACS were screened immediately from admission to Cardiac intensive care unit (CICU) and managed according to the ACS clinical pathway if the patients fulfilled the inclusion criteria. The clinical pathway was implemented by clinical pathway teams daily in three shifts in CICU until patient discharge. The expected daily outcomes were assessed daily from admission until discharge. The main components of clinical pathway are:
Assessment and initial treatment; Consultation; Diagnostics and laboratory; Medications and treatment intervention; Nutrition support; Mobility \& activity; Psychosocial support and Discharge planning. The clinical pathway implemented as the following:

(1) Clinical pathway intervention in the first 2 hours of admission included: continuous ECG monitoring ST segment, insert intravenous access, $\mathrm{O}_{2}$ therapy as order as initial intervention, or primary PCI, assessment of heart, respiratory sound, vital signs, $\mathrm{O}_{2}$ saturation, chest pain, bleeding tendency, cardiac enzymes and other laboratory investigation and insert Foley catheter, giving thrombolytic medication if there's ST elevation within 30 min of entering hospital; Nutrition including nothing per month; Mobility \& activity including bed rest; Psychosocial support including inform family \& patient about diagnosis, address immediate concerns, and review pain scale.

(2) Clinical pathway intervention after 2 hours of admission included: Continuous cardiac monitoring/telemetry, assessment of vital signs, $\mathrm{O}_{2}$ Sat every $4 \mathrm{hrs} \&$ PRN (every $2 \mathrm{hrs}$ for thrombolytic patients, respiratory sound, Pain assessment, assess for signs of heart failure or bleeding, monitor intake and output, assessment of mental status (oriented to time, person \& place); Diagnostics/laboratory including ECG \& cardiac markers, ECG with pain, Chest X-ray if not don in ER; Medications include low molecular weight heparin, CIOPIDOGREL, TICAGRELOL, GP II b III a, beta blockers, ACE inhibitor/ARB and statins. Nutrition clear fluid, Full fluids, healthy heart diet as tolerated; Activity level 1 as tolerated for (MI \& angina) were bed rest, bed side commode privilege if stable., feed self., assisted bath., foot exercise, deep breathing/ coughing, Activity level 2 as tolerated for Angina patient only including sit up 2 min (TID or meal 3) and bath room privilege; Psychosocial support including oriented patient to unit and procedure, introduce patient pathway, encourage questions and review visiting guidelines; Discharge planning including assess for transfer for telemetry, family physician notified and assess discharge criteria.

(3) Clinical pathway intervention on the $2^{\text {nd }}$ day included: Assessment; continuous cardiac monitoring, vital signs with $\mathrm{O}_{2}$ Sat every 4hrs and PRN, chest assessment, pain assessment; assess for signs of heart failure, bleeding \& peripheral edema, monitor intake and output, assess bowel routine, mental status (oriented to time, person \& place); Diagnostics /laboratory as ECG with pain, chest X-ray if not done previously, blood work as order; Medications as doctor order; Treatments intervention as $\mathrm{O}_{2} \mathrm{PRN}$, IV /saline lock (discontinue in angina patient); Nutrition as healthy heart diet or special diet if ordered. Activity level 2 as tolerated for (MI $\&$ angina PT); sit up 20 min (TID or meals), bathroom privilege and assisted bath. Activity level 3; up in bed, set up for meals, shower and walk in hall. Activity level 4 activity as order and stairs; Psychosocial support; Patient encouraged to ask questions; Discharge planning for patient with angina ECHO appointment arranged, discharge plans discussed with 


\section{PTs/family.}

(4) Clinical pathway intervention on the $3^{\text {rd }}$ day included: Assessment of vital signs with $\mathrm{O}_{2}$ SAT every 8 hrs \& PRN, assessment of chest, Pain, peripheral edema and mental status (oriented to time, person \& place); Diagnostics /laboratory; ECG with pain, blood work as order and INR if on warfarin; Medications see medication administration record; Nutrition; healthy heart diet or special diet if ordered; Activity level 3 including up in room, set up for meals, bathroom, shower privilege and walk in hall; Psychosocial support including review patient pathway; Discharge planning including assess need for telemetry to medical unit and assess needs for discharge.

(5) Clinical pathway intervention in the $4^{\text {th }}$ day included: Assessment of vital signs with $\mathrm{O}_{2}$ Sat twice \& PRN, assessment of respiratory sound, Pain and mental status (oriented to time, person \& place); Diagnostics /laboratory were ECG with pain; Medications; see medication administration record; Nutrition including healthy heart diet or special diet if ordered; Activity level 4 Activity as tolerated, stairs, reinforced activity level; psychosocial support as review patient pathway; Discharge planning; ECHO appointment arranged, stress test arranged, assess discharge criteria daily. If patients stay more than 4 days, Day 4 may be repeated. A physician's order is required on the medication and diagnostic choices and is required to transfer the patient out of ICU, or discharge home. Data were collected from October 2016 to February 2017.

\subsubsection{Evaluation Phase}

This phase consisted of comparing the outcomes for both groups (study $\mathrm{CP}$ group and control group) including: physiological parameters, length of ICU stay, anxiety level and status of patient during discharge using tool II. Evaluating of content validity of the ACS clinical pathway was evaluated by 10 academic and clinical experts using tool III.

Statistical analysis: The analysis was performed using statistical software SPSS version 23. For quantitative data, the range, mean and standard deviation were calculated. For qualitative data, a comparison between groups before and after intervention was done by using Chi-square test. For a comparison between more than two means, the ANOVA Fvalue was calculated. A significance was adopted at $\mathrm{P}<0.05$ for interpretation of results of tests of significance.

\section{Results}

Table 1 represents distribution of studied patients according to socio demographic characteristics among the study and control groups. The present study showed that the mean age of patents in control group was (53.00 \pm 7.83 years), while it was (55.47 \pm 7.49 years) in the study group with none significant difference was observed between them with $\mathrm{P}=0.218$. In relation to sex, most of patients in control group (76.7\%) and study group (73.3\%) were male.

Table 1. Distribution of studied sample according to sociodemographic characteristics.

\begin{tabular}{|c|c|c|c|c|c|}
\hline \multirow{3}{*}{ Characteristics } & \multicolumn{4}{|c|}{ The studied sample $(\mathrm{n}=60)$} & \multirow{3}{*}{$\begin{array}{l}\chi^{2} \\
\mathbf{P}\end{array}$} \\
\hline & \multicolumn{2}{|c|}{ Control group $(n=30)$} & \multicolumn{2}{|c|}{ Study group $(n=30)$} & \\
\hline & $\mathbf{N}$ & $\%$ & $\mathbf{N}$ & $\%$ & \\
\hline Age & & & & & $\mathrm{t}=1.552$ \\
\hline Mean \pm SD & \multicolumn{2}{|l|}{$53.00 \pm 7.83$} & \multicolumn{2}{|l|}{$55.47 \pm 7.49$} & $\mathrm{P}=0.218$ \\
\hline \multicolumn{6}{|l|}{ Sex } \\
\hline male & 23 & 76.7 & 22 & 73.3 & $\mathrm{FE}$ \\
\hline female & 7 & 23.3 & 8 & 26.7 & 0.766 \\
\hline \multicolumn{6}{|l|}{ Marital status } \\
\hline married & 18 & 60.0 & 27 & 90.0 & \\
\hline single & 1 & 3.3 & 0 & 0.0 & 7.371 \\
\hline widow & 11 & 36.7 & 3 & 10.0 & $0.025^{*}$ \\
\hline \multicolumn{6}{|l|}{ Level of education } \\
\hline read and write & 11 & 36.7 & 9 & 30.0 & \\
\hline Secondary school & 7 & 23.3 & 6 & 20.0 & 0.610 \\
\hline University education & 12 & 40.0 & 15 & 50.0 & 0.737 \\
\hline \multicolumn{6}{|l|}{ Diagnosis } \\
\hline STEMI & 19 & 63.3 & 21 & 70.0 & F E \\
\hline NSTEMI & 11 & 36.6 & 9 & 30.0 & 0.392 \\
\hline
\end{tabular}

FE: Fisher's Exact Test* Significant at level $\mathrm{P}<0.05$.

In relation to marital status, the present study showed that more than half $(60 \%)$ of the control group were married, while majority (90\%) of the study group were married with a significant difference was found between control and study group where $\mathrm{P}=(0.025)$. Concerning level of education, more than one third $(40 \%)$ of the control group had university education compared to $(50 \%)$ in the study group. Regarding diagnosis, more than two third $(63.3 \%)$ of the control group diagnosed as STEMI compared to $(70 \%)$ of patients in study group. 
Table 2. Distribution of studied sample according to medical history.

\begin{tabular}{|c|c|c|c|c|c|c|}
\hline \multirow{3}{*}{ Items } & \multicolumn{4}{|c|}{ The studied patients $(\mathrm{n}=60)$} & \multirow{3}{*}{$\chi^{2}$} & \multirow{3}{*}{$\mathbf{P}$} \\
\hline & \multicolumn{2}{|c|}{ Control group $(n=30)$} & \multicolumn{2}{|c|}{ Study group $(n=30)$} & & \\
\hline & $\mathbf{N}$ & $\%$ & $\mathbf{N}$ & $\%$ & & \\
\hline \multicolumn{7}{|l|}{ Medical history } \\
\hline HTN & 18 & 60.0 & 12 & 40.0 & 2.400 & 0.121 \\
\hline Diabetes mellitus & 20 & 66.7 & 8 & 26.7 & 9.643 & $0.002 *$ \\
\hline Hyperlipidaemia & 20 & 66.7 & 13 & 43.3 & 3.30 & 0.069 \\
\hline COPD & 10 & 33.3 & 0 & 0.0 & 12.0 & $0.001 *$ \\
\hline Rheumatoid & 4 & 13.3 & 2 & 6.7 & 0.741 & 0.389 \\
\hline LVH & 2 & 6.7 & 0 & 0.0 & 2.069 & 0.150 \\
\hline Family history of CAD & 23 & 76.7 & 18 & 60.0 & 1.926 & 0.165 \\
\hline Smoking history & 20 & 66.7 & 14 & 46.7 & 2.443 & 0.118 \\
\hline
\end{tabular}

* Significant at level $\mathrm{P}<0.05$

Table 2 shows distribution of the studied patients according to medical history. Concerning medical history, hypertension was encountered among $60.0 \%$ of the control group compared to $40.0 \%$ of the study group, without significant difference. Similar percentage $(66.7 \%)$ of the control group had past history of diabetes mellitus and hyperlipidemia compared to $26.7 \%$ and $43.3 \%$ of patients in study group. Also more than three quarters (76.7\%) of control group had family history of coronary artery diseases compared to $60.0 \%$ of study group. As for smoking history, more than two third $(66.7 \%)$ of patients in control group were smoker compared to $46.7 \%$ of patients in study group with no significant difference between them.

Table 3. Distribution of studied sample according to laboratory results.

\begin{tabular}{|c|c|c|c|c|}
\hline \multirow{2}{*}{ Laboratory investigations } & \multicolumn{2}{|c|}{ The studied sample Mean \pm SD } & \multirow{2}{*}{$\mathbf{t}$} & \multirow{2}{*}{$\mathbf{P}$} \\
\hline & Control group & Study group & & \\
\hline \multicolumn{5}{|l|}{ Lipid profile } \\
\hline cholesterol & $247.90 \pm 72.19$ & $263.53 \pm 118.22$ & 0.035 & 0.852 \\
\hline HDL & $56.83 \pm 37.742$ & $67.89 \pm 56.418$ & 0.382 & 0.539 \\
\hline LDL & $225.27 \pm 95.495$ & $249.77 \pm 156.99$ & 0.796 & 0.376 \\
\hline \multicolumn{5}{|l|}{ Cardiac enzymes } \\
\hline CK-MB & $83.47 \pm 65.957$ & $56.84 \pm 39.575$ & 3.595 & 0.063 \\
\hline \multicolumn{5}{|c|}{ Electrolytes and blood glucose level } \\
\hline $\mathrm{Na}+$ & $134.97 \pm 18.27$ & $139.54 \pm 3.796$ & 1.802 & 0.185 \\
\hline $\mathrm{K}+$ & $3.93 \pm 0.583$ & $3.96 \pm .493$ & 0.063 & 0.803 \\
\hline RBS & $323.97 \pm .179 .88$ & $144.40 \pm .57 .60$ & 27.168 & $0.00 *$ \\
\hline
\end{tabular}

* Significant at level $\mathrm{P}<0.05$.

Table 3 demonstrates distribution of studied sample according to laboratory investigation, concerning lipid profile and cardiac enzymes, the present study revealed that increased mean score of cholesterol, LDL level and CK-MB and decreased HDL level for both groups without significant difference. As regard electrolytes and blood glucose level, it was noticed that no significant difference was observed between two groups regarding $\mathrm{Na}, \mathrm{K}$. However there was increased of random blood sugar $(323.97 \pm .179 .877)$ of control group compared to $(144.40 \pm .57 .60)$ for the study group with significant difference where $\mathrm{P}=0.00$.

Figure 1 presents distribution of studied sample according to Troponin level. The present study showed that, more than two third $(76.7 \%)$ of control groups had negative troponin level compared to $63.3 \%$ of study group. However, $23.3 \%$ of control group had positive troponin level compared to $36.7 \%$ of study group.

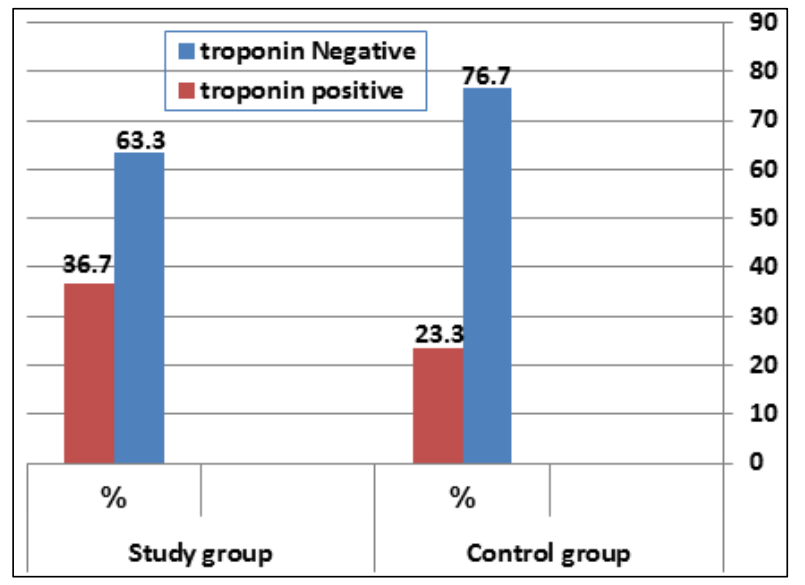

Figure 1. Distribution of studied sample according to Troponin level. 
Table 4. Distribution of studied sample according to physiological response (vital signs) throughout periods of study.

\begin{tabular}{|c|c|c|c|c|}
\hline \multirow{2}{*}{ Vital signs } & \multicolumn{2}{|c|}{ The studied sample Mean \pm SD } & \multirow{2}{*}{$\mathbf{t}$} & \multirow{2}{*}{$\mathbf{P}$} \\
\hline & Control group & Study group & & \\
\hline \multicolumn{5}{|l|}{ Temperature } \\
\hline On admission & $37.68 \pm 0.598$ & $37.82 \pm 0.343$ & 1.180 & 0.282 \\
\hline After 2 hrs & $37.39 \pm 0.496$ & $37.51 \pm 0.173$ & 1.567 & 0.216 \\
\hline $2^{\text {nd }}$ day & $37.25 \pm 0.567$ & $37.45 \pm 0.153$ & 3.593 & 0.063 \\
\hline On discharge & $37.46 \pm 11.348$ & $37.43 \pm 0.173$ & 3.683 & 0.06 \\
\hline $\mathrm{F}, \mathrm{P}$ & $3.701,0.014 *$ & $19.557,0.00 *$ & & \\
\hline \multicolumn{5}{|l|}{ Pulse } \\
\hline On admission & $98.10 \pm 21.902$ & $97.83 \pm 10.850$ & 0.004 & 0.953 \\
\hline After 2 hrs. & $107.80 \pm 29.989$ & $89.67 \pm 7.796$ & 10.274 & $0.002 *$ \\
\hline $2^{\text {nd }}$ day & $99.60 \pm 24.890$ & $81.87 \pm 7.986$ & 13.807 & $0.000 *$ \\
\hline On discharge & $83.77 \pm 36.205$ & $80.43 \pm 7.380$ & 0.244 & 0.623 \\
\hline $\mathrm{F}, \mathrm{P}$ & $3.618,0.015^{*}$ & $26.034,0.00 *$ & & \\
\hline \multicolumn{5}{|l|}{ Respiration } \\
\hline On admission & $31.80 \pm 3.585$ & $30.27 \pm 3.759$ & 2.613 & 0.111 \\
\hline After 2 hrs. & $25.30 \pm 2.602$ & $24.37 \pm 2.684$ & 1.870 & 0.177 \\
\hline $2^{\text {nd }}$ day & $23.77 \pm 6.867$ & $23.77 \pm 2.967$ & 0.00 & 1.00 \\
\hline On discharge & $20.37 \pm 9.604$ & $21.23 \pm 2.128$ & 0.233 & 0.631 \\
\hline $\mathrm{F}, \mathrm{P}$ & $17.341,0.00 *$ & $50.543,0.00 *$ & & \\
\hline \multicolumn{5}{|l|}{ Systolic B/P } \\
\hline On admission & $111.67 \pm 5.241$ & $130.33 \pm 19.384$ & 6.462 & $0.014 *$ \\
\hline After 2 hrs. & $99.00 \pm 29.636$ & $123.00 \pm 17.646$ & 14.525 & $0.00 *$ \\
\hline $2^{\text {nd }}$ day & $107.33 \pm 7.156$ & $118.67 \pm 14.320$ & 4.088 & $0.048^{*}$ \\
\hline On discharge & $91.67 \pm 42.838$ & $120.67 \pm 3.651$ & 13.650 & $0.00 *$ \\
\hline $\mathrm{F}, \mathrm{P}$ & $2.020,0.115$ & $3.441,0.019^{*}$ & & \\
\hline \multicolumn{5}{|l|}{ Diastolic B/P } \\
\hline On admission & $68.33 \pm 19.313$ & $80.67 \pm 12.015$ & 8.820 & $0.004 *$ \\
\hline After 2 hrs. & $63.33 \pm 19.711$ & $79.33 \pm 9.803$ & 15.848 & $0.00^{*}$ \\
\hline $2^{\text {nd }}$ day & $66.80 \pm 17.036$ & $77.77 \pm 9.387$ & 9.536 & $0.003 *$ \\
\hline On discharge & $59.33 \pm 28.276$ & $75.90 \pm 5.320$ & 9.946 & $0.003 *$ \\
\hline $\mathrm{F}, \mathrm{P}$ & $1.038,0.379$ & $1.419,0.241$ & & \\
\hline
\end{tabular}

* Significant at level $\mathrm{P}<0.05$.

Table 4, represents distribution of the studied patients according to physiological response (vital signs) throughout periods of study.

This table revealed that a significant changes among control and study group from admission to discharge regarding mean scores of body temperature, pulse and respiration rate while the mean score of body temperature, pulse and respiration rate of control group on admission were (37.68 $\pm 0.598,98.10 \pm 21.902$ and $31.80 \pm 3.585$ respectively) then decreased to $(37.46 \pm 11.348,83.77 \pm 36.205,20.37 \pm$ 9.604 respectively) on discharge with $\mathrm{P}=0.014,0.00$ and 0.015 respectively. Also, the mean score of body temperature, pulse and respiration rate of study group on admission were $(37.82 \pm 0.343,97.83 \pm 10.850$ and $30.27 \pm$ 3.759 respectively) then decreased to $(37.43 \pm 0.173,80.43 \pm$ 7.380 and $21.23 \pm 2.128$ respectively) on discharge with $\mathrm{P}=0.00$ respectively.

Moreover, it was found a significant difference between the mean score of pulse of control and study group (107.80 \pm 29.989 and $89.67 \pm 7.796 \mathrm{~b} / \mathrm{m}$ respectively) after 2 hours of admission then decreased to $(99.60 \pm 24.890$ and $81.87 \pm 7.986 \mathrm{~b} / \mathrm{m}$ ) on $2^{\text {nd }}$ day of admission, with $\mathrm{P}=0.002$ and 0.00 respectively. In relation to blood pressure, there was a significant decreased in systolic and diastolic blood pressure mean scores of control and study group throughout period of study; on admission, $2^{\text {nd }}$ day and on discharge where $\mathrm{P}<$ 0.05 . Although there was a significant change in mean score of blood pressure but these changes was within the normal ranges of physiological variables where $\mathrm{P}<0.05$.

Table 5, shows distribution of the studied patients according to mean scores of physiological parameter (cardiopulmonary response) throughout period of study. As regards mean arterial pressure (MAP), there was a significant difference between control and study group on admission, after $2 \mathrm{hrs}$ and on discharge where $\mathrm{P}=0.008,0.00,0.006$ respectively. Concerning mean score of central venous pressure (CVP) and oxygen saturation $\left(\mathrm{O}_{2}\right.$ Sat) there was significant increased mean score of central venous pressure among control group compared to study group on admission, after $2 \mathrm{hrs}$ and on $2^{\text {nd }}$ day of admission with $\mathrm{P}=0.013,0.007$ and 0.001 respectively. While a significant difference was found between control and study group only after $2 \mathrm{hrs}$ of admission for oxygen saturation $\left(\mathrm{O}_{2}\right.$ Sat $)$ with $\mathrm{P}=0.028$.

However, there was a significant difference among study group regarding mean score of mean arterial pressure and CVP throughout period of study where mean score of mean arterial pressure was $(66.00 \pm 9.505)$ on admission and decreased to $(62.00 \pm 2.816)$ on discharge with $\mathrm{P}=(0.021)$ and CVP was $(8.37 \pm 1.066)$ on admission and decreased to (7.67 \pm .711 ) on discharge with $\mathrm{P}=0.005$. Also there was a significant difference among control and study group regarding $\mathrm{O}_{2}$ Sat, where it was $(80.97 \pm 13.279,89.44 \pm 4.159$ respectively) on admission and become (96.10 \pm 3.506 , $97.22 \pm 2.014$ respectively) on discharge for control and study 
group with $\mathrm{P}=0.017$ and 0.00 respectively.

Table 5. Distribution of studied sample according to mean scores of physiological parameters (cardiopulmonary response).

\begin{tabular}{|c|c|c|c|c|}
\hline \multirow{2}{*}{ Physiological parameters } & \multicolumn{2}{|c|}{ The studied sample Mean \pm SD } & \multirow{2}{*}{$\mathbf{t}$} & \multirow{2}{*}{$\mathbf{P}$} \\
\hline & Control group & Study group & & \\
\hline \multicolumn{5}{|l|}{ Mean arterial pressure } \\
\hline On admission & $56.17 \pm 17.205$ & $66.00 \pm 9.505$ & 7.508 & $0.008 *$ \\
\hline After $2 \mathrm{hrs.}$ & $50.83 \pm 15.261$ & $64.50 \pm 5.309$ & 21.461 & $0.00^{*}$ \\
\hline $2^{\text {nd }}$ day & $56.33 \pm 13.954$ & $61.67 \pm 5.142$ & 3.859 & 0.054 \\
\hline On discharge & $50.40 \pm 21.946$ & $62.00 \pm 2.816$ & 8.246 & $0.006^{*}$ \\
\hline $\mathrm{F}, \mathrm{P}$ & $1.057,0.370$ & $3.363,0.021 *$ & & \\
\hline \multicolumn{5}{|l|}{ Central venous pressure } \\
\hline On admission & $11.87 \pm 7.408$ & $8.37 \pm 1.066$ & 6.561 & $0.013 *$ \\
\hline After 2 hrs. & $11.70 \pm 7.818$ & $7.67 \pm .844$ & 7.894 & $0.007 *$ \\
\hline $2^{\text {nd }}$ day & $12.17 \pm 6.914$ & $7.87 \pm .776$ & 11.46 & $0.001 *$ \\
\hline On discharge & $9.67 \pm 6.239$ & $7.67 \pm .711$ & 3.044 & 0.086 \\
\hline $\mathrm{F}, \mathrm{P}$ & $0.768,0.514$ & $4.429,0.005^{*}$ & & \\
\hline \multicolumn{5}{|l|}{$\mathrm{O} 2$ saturation } \\
\hline On admission & $80.97 \pm 13.279$ & $89.44 \pm 4.159$ & 3.855 & 0.054 \\
\hline After 2 hrs. & $89.10 \pm 10.425$ & $94.47 \pm 3.980$ & 5.076 & $0.028 *$ \\
\hline $2^{\text {nd }}$ day & $97.37 \pm 1.217$ & $97.30 \pm .750$ & 0.065 & 0.799 \\
\hline On discharge & $96.10 \pm 3.506$ & $97.22 \pm 2.014$ & 3.663 & 0.061 \\
\hline $\mathrm{F}, \mathrm{P}$ & $3.526,0.017^{*}$ & $46.927,0.00 *$ & & \\
\hline
\end{tabular}

* Significant at level $\mathrm{P}<0.05$.

Table 6. Distribution of studied sample according to changes in heart sounds throughout period of study.

\begin{tabular}{|c|c|c|c|c|c|c|}
\hline \multirow{3}{*}{ Heart sound changes } & \multicolumn{4}{|c|}{ The studied sample $(\mathrm{n}=60)$} & \multirow{3}{*}{$\chi^{2}$} & \multirow{3}{*}{$\mathbf{P}$} \\
\hline & \multicolumn{2}{|c|}{ Control group $(n=30)$} & \multicolumn{2}{|c|}{ Study group $(\mathrm{n}=\mathbf{3 0})$} & & \\
\hline & $\mathbf{N}$ & $\%$ & $\mathbf{N}$ & $\%$ & & \\
\hline \multicolumn{7}{|l|}{ Third heart sound (S3) } \\
\hline On admission & 4 & 13.3 & 0 & 0.0 & 4.286 & $0.038 *$ \\
\hline After $2 \mathrm{hrs}$. & 4 & 13.3 & 0 & 0.0 & 4.286 & $0.038 *$ \\
\hline $2^{\text {nd }}$ day & 6 & 20.0 & 0 & 0.0 & 6.667 & $0.010^{*}$ \\
\hline On discharge & 4 & 13.3 & 0 & 0.0 & 4.286 & $0.038 *$ \\
\hline $\begin{array}{l}\chi^{2}, P \\
\text { fourth heart sound (S4) }\end{array}$ & \multicolumn{2}{|c|}{$0.784,0.853$} & \multicolumn{2}{|l|}{-} & & \\
\hline On admission & 12 & 40.0 & 0 & 0.0 & 15.0 & $0.00 *$ \\
\hline After 2 hrs. & 12 & 40.0 & 0 & 0.0 & 15.0 & $0.00 *$ \\
\hline $2^{\text {nd }}$ day & 3 & 10.0 & 0 & 0.0 & 3.158 & 0.761 \\
\hline On discharge & 1 & 3.3 & 0 & 0.0 & 1.017 & 0.313 \\
\hline$\chi^{2}, \mathrm{P}$ & \multicolumn{2}{|c|}{$19.006,0.00 *$} & - & & & \\
\hline
\end{tabular}

* Significant at level $\mathrm{P}<0.05$.

Table 6 illustrates distribution of the studied patients according to changes in heart sounds throughout period of study, in relation to third heart sound (S3), it was noticed that less than one quarter $(13.3 \%)$ of the control patients had audible S3 on admission, after 2 hours of admission and on discharge while $20 \%$ of them had audible S3 on $2^{\text {nd }}$ day of admission, while in study group the S3 heart sound not present throughout period of study with a significant difference was found among control and studied group where $\mathrm{P}=0.038,0.038,0.010$ and 0.038 respectively.

Concerning fourth heart sound (S4), more than one third $(40.0 \%)$ of the control group had auscultated S4 on admission and after 2 hours of admission, while in study group the S4 heart sound was not auscultated throughout period of study with a significant difference was found among control and studied group where $\mathrm{P}=(0.000$ and 0.000$)$ respectively. The study revealed that a significant difference among control group in relation S4 from admission to discharge where $\mathrm{F}, \mathrm{P}=(19.006,0.000)$.

Table 7, shows distribution of the studied patients according to changes in respiratory sounds throughout period of study, the present study showed that small percentage (20.0\% and $16.7 .0 \%$ respectively) of the control group had audible crackles and wheezing on $2^{\text {nd }}$ day of admission, while in study group the crackles and wheezing sound was not present on 2nd day of admission with a significant difference between two groups where $\mathrm{P}=0.010$ and 0.020 respectively. As regard to persistence cough, it was found that (16.7.0\%) of the control group had persistence cough on admission and after 2 hours, while $13.3 \%$ of them had persistence cough on $2^{\text {nd }}$ day of admission. On the other hand, no any patients in the study group had persistence cough throughout period of study. Also, a significant difference was found among control and studied group where $\mathrm{P}=(0.020,0.020$, and 0.038$)$ respectively. 
Table 7. Distribution of studied sample according to changes in respiratory sounds throughout period of study.

\begin{tabular}{|c|c|c|c|c|c|c|}
\hline \multirow{3}{*}{ Changes in respiratory sound } & \multicolumn{4}{|c|}{ The studied sample $(n=60)$} & \multirow{3}{*}{$\chi^{2}$} & \multirow{3}{*}{$\mathbf{P}$} \\
\hline & \multicolumn{2}{|c|}{ Control group $(\mathrm{n}=\mathbf{3 0})$} & \multicolumn{2}{|c|}{ Study group $(\mathrm{n}=\mathbf{3 0})$} & & \\
\hline & $\mathbf{N}$ & $\%$ & $\mathbf{N}$ & $\%$ & & \\
\hline \multicolumn{7}{|l|}{ Crackles } \\
\hline On admission & 7 & 23.3 & 4 & 13.3 & 1.002 & 0.317 \\
\hline After 2 hrs. & 8 & 26.7 & 5 & 16.7 & 0.884 & 0.347 \\
\hline $2^{\text {nd }}$ day & 6 & 20.0 & 0 & 0.0 & 6.667 & $0.01 *$ \\
\hline On discharge & 3 & 10.0 & 0 & 0.0 & 3.158 & 0.076 \\
\hline$\chi^{2}, \mathrm{P}$ & \multirow{2}{*}{\multicolumn{2}{|c|}{$2.917,0.405$}} & \multirow{2}{*}{\multicolumn{2}{|c|}{$9.970,0.019^{*}$}} & & \\
\hline \multicolumn{3}{|l|}{ Wheezing } & & & & \\
\hline On admission & 5 & 16.7 & 1 & 3.3 & 2.963 & 0.085 \\
\hline After $2 \mathrm{hrs}$. & 5 & 16.7 & 2 & 6.7 & 1.456 & 0.228 \\
\hline $2^{\text {nd }}$ day & 5 & 16.7 & 0 & 0.0 & 5.455 & $0.02 *$ \\
\hline On discharge & 2 & 6.7 & 0 & 0.0 & 2.069 & 0.150 \\
\hline$\chi^{2}, \mathrm{P}$ & \multirow{2}{*}{\multicolumn{2}{|c|}{$1.85,0.604$}} & \multirow{2}{*}{\multicolumn{2}{|c|}{$3.761,0.288$}} & & \\
\hline \multicolumn{3}{|l|}{ Persistent cough } & & & & \\
\hline On admission & 5 & 16.7 & 0 & 0.0 & 5.455 & $0.02 *$ \\
\hline After 2 hrs. & 5 & 16.7 & 0 & 0.0 & 5.455 & $0.02 *$ \\
\hline $2^{\text {nd }}$ day & 4 & 13.3 & 0 & 0.0 & 4.286 & $0.038^{*}$ \\
\hline On discharge & 3 & 10.0 & 0 & 0.0 & 3.158 & 0.076 \\
\hline$\chi^{2}, \mathrm{P}$ & \multicolumn{2}{|c|}{$0.754,0.86$} & \multicolumn{2}{|l|}{-} & & \\
\hline
\end{tabular}

* Significant at level $\mathrm{P}<0.05$.

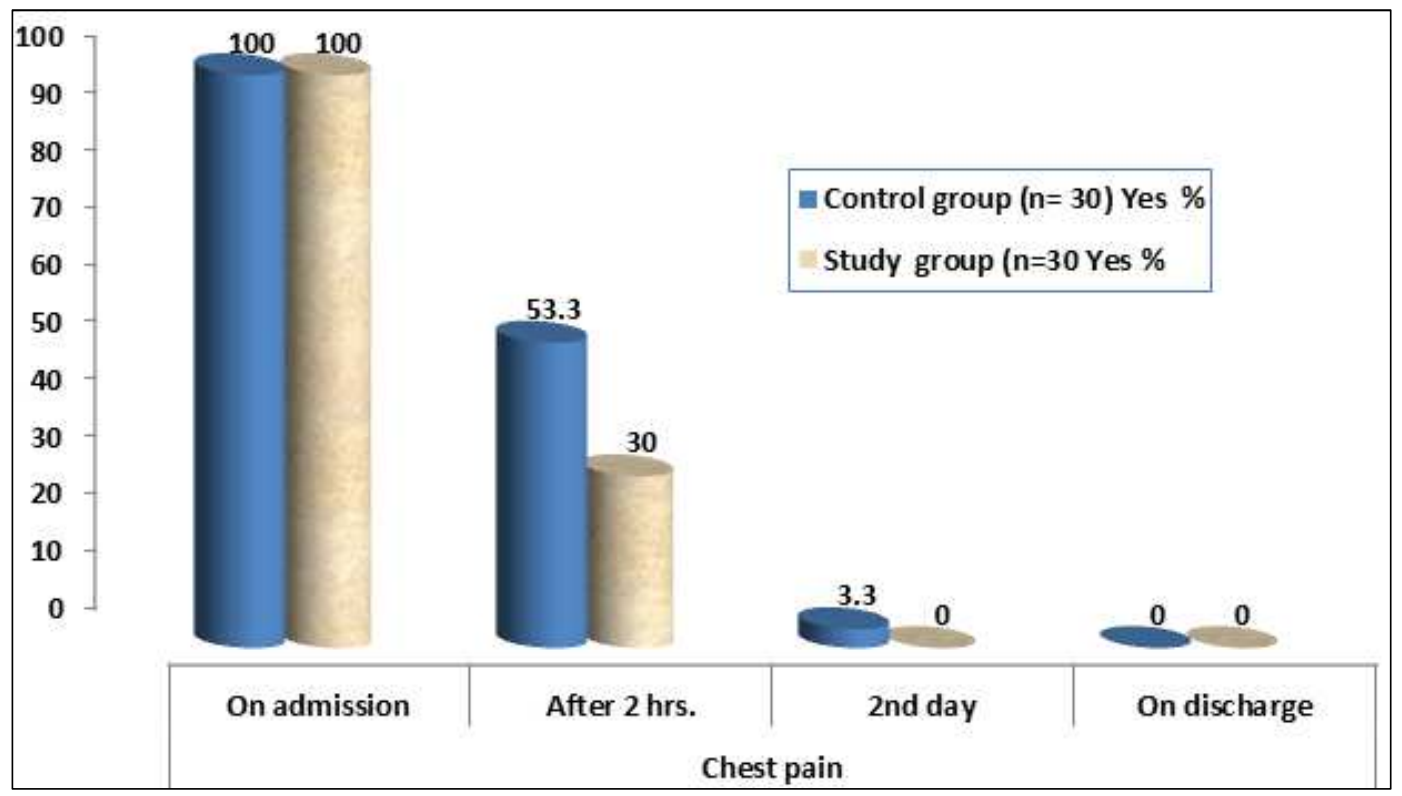

Figure 2. Distribution of studied sample according to chest pain.

Figure 2 shows distribution of the studied patients according to chest pain throughout period of study, it was found that all the patients $(100.0 \%)$ in the control group had chest pain on admission and this percentage decreased to $(53.3 \%)$ after 2 hours of admission, $(3.3 \%)$ on the $2^{\text {nd }}$ day of admission and $(0.0 \%)$ on discharge, while in study group the chest pain on admission was $(100.0 \%)$ then decreased to $(30.0 \%)$ after 2 hours of admission, $(0.0 \%)$ on the $2^{\text {nd }}$ day of admission, and $(0.0 \%)$ on discharge.

Table 8. Distribution of studied sample according to fluid intake and output throughout period of study.

\begin{tabular}{|c|c|c|c|c|}
\hline \multirow{2}{*}{ Intake and output } & \multicolumn{2}{|c|}{ The studied sample Mean \pm SD } & \multirow{2}{*}{$\mathbf{Z}$} & \multirow{2}{*}{$\mathbf{P}$} \\
\hline & Control group & Study group & & \\
\hline \multicolumn{5}{|l|}{ fluid Intake } \\
\hline $1^{\text {st }}$ day of admission & $1081.67 \pm 996.068$ & $1443.33 \pm 797.705$ & 2.410 & 0.126 \\
\hline $2^{\text {nd }}$ day & $1180.00 \pm 644.553$ & $1646.00 \pm 644.553$ & 7.127 & $0.01 *$ \\
\hline $3^{\text {rd }}$ day & $1263.33 \pm 466.449$ & $1732.67 \pm 496.007$ & 9.509 & $0.003 *$ \\
\hline On discharge & $1206.67 \pm 846.467$ & $1882.00 \pm 969.271$ & 8.262 & $0.006^{*}$ \\
\hline
\end{tabular}




\begin{tabular}{|c|c|c|c|c|}
\hline \multirow{2}{*}{ Intake and output } & \multicolumn{2}{|c|}{ The studied sample Mean \pm SD } & \multirow{2}{*}{$\mathbf{Z}$} & \multirow{2}{*}{$\mathbf{P}$} \\
\hline & Control group & Study group & & \\
\hline $\begin{array}{l}\text { F, P } \\
\text { fluid output }\end{array}$ & $0.295,0.829$ & $1.66,0.179$ & & \\
\hline $1^{\text {st }}$ day of admission & $825.00 \pm 764.825$ & $1308.33 \pm 790.579$ & 5.792 & $0.019 *$ \\
\hline $2^{\text {nd }}$ day & $997.00 \pm 848.049$ & $1666.67 \pm 920.207$ & 8.591 & $0.005^{*}$ \\
\hline $3^{\text {rd }}$ day & $991.67 \pm 941.672$ & $1392.00 \pm 636.339$ & 3.722 & 0.059 \\
\hline On discharge & $969.00 \pm 867.252$ & $1610.00 \pm 725.092$ & 9.646 & $0.003 *$ \\
\hline
\end{tabular}

* Significant at level $\mathrm{P}<0.05$.

Table 8, represents distribution of the studied patients according to intake and output throughout period of study, in relation to mean score of fluid intake, a significant difference was found between control and study group on $2^{\text {nd }}$ day, $3^{\text {rd }}$ day and on discharge where $\mathrm{P}=0.010,0.003,0.006$ respectively. Concerning to mean score of fluid output, a significant difference was found between control and study group on the $1^{\text {st }}$ day, $2^{\text {nd }}$ day and on discharge where $\mathrm{P}=$ $(0.019,0.005$, and 0.003$)$ respectively.

Table 9. Distribution of studied sample according to ABG result throughout period of study.

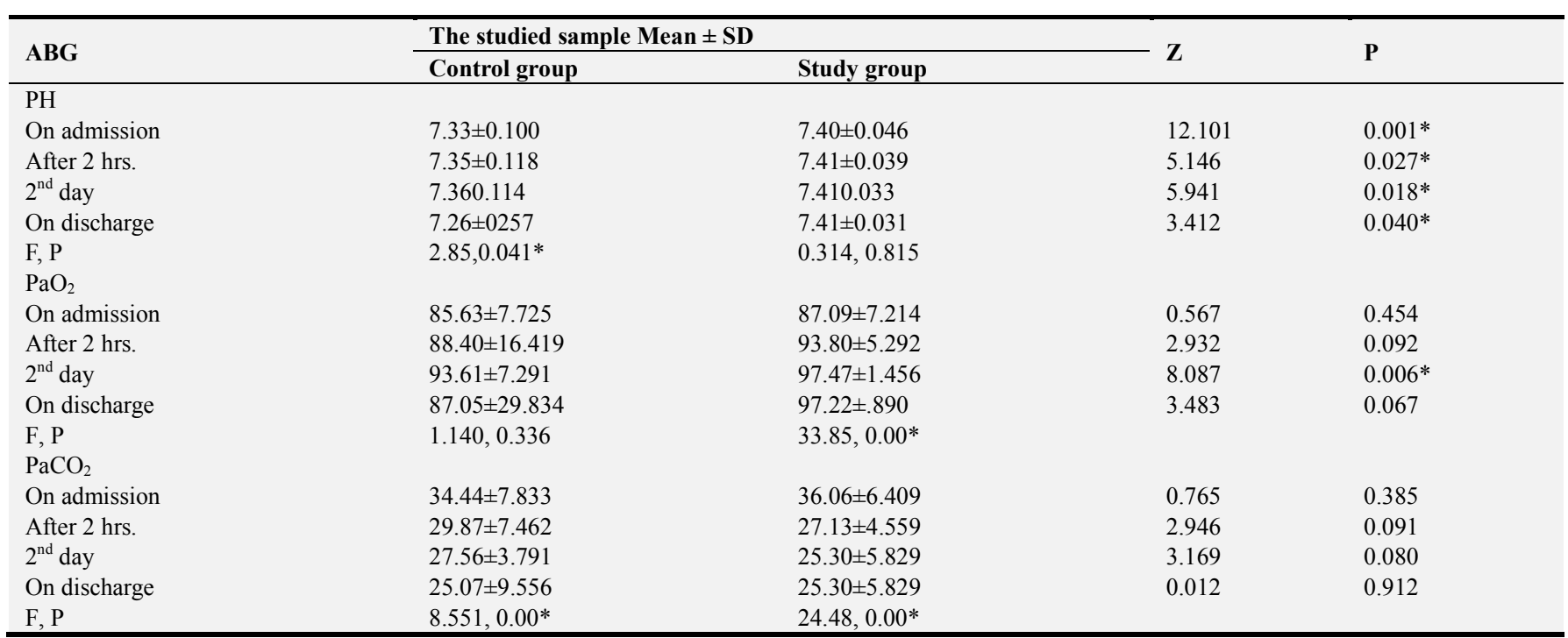

* Significant at level $\mathrm{P}<0.05$.

Table 9, Illustrates distribution of studied sample according to $A B G$ result throughout period of study, it was observed that the mean value of $\mathrm{PH}$ of patients in control group on admission was $(7.33 \pm 0.100)$ and become (7.26 \pm 0257$)$ on discharge with significant difference where $\mathrm{P}=0.041$. While in the study group it was $(7.40 \pm 0.046)$ on admission and become $(7.41 \pm 0.031)$ on discharge. Also, a significant difference was observed among control and study group through period of study on admission, after $2 \mathrm{hrs}$ and on $2^{\text {nd }}$ day where $\mathrm{P}=0.001,0.027$ and 0.018 respectively.

Concerning $\mathrm{PaO}_{2}$, the mean value of $\mathrm{PaO}_{2}$ among control group on admission was $(85.63 \pm 7.725)$ and increased to
$87.05 \pm 29.834$ on discharge, while it was $(87.09 \pm 7.214)$ among study group on admission and increased to (97.22 \pm .890$)$ on discharge. Moreover, a significant difference was found among control and study group on $2^{\text {nd }}$ day where $\mathrm{P}=(0.006)$.

Regarding mean value of $\mathrm{PaCO}_{2}$, it was (34.44 7.833) on admission and decreased to $(25.07 \pm 9.556)$ on discharge in the control group, while in the study group, it was (36.06 \pm 6.409$)$ on admission and decreased to $(25.30 \pm 5.829)$ on discharge. With none significant difference was found between control and study group where $\mathrm{P}=0.385$ and 0.912 respectively.

Table 10. Distribution of studied sample according to acute coronary syndrome complications throughout period of study.

\begin{tabular}{|c|c|c|c|c|c|c|}
\hline \multirow{3}{*}{ Complications of acute coronary syndrome } & \multicolumn{4}{|c|}{ Studied patients $(\mathrm{n}=60)$} & \multirow{3}{*}{$\chi^{2}$} & \multirow{3}{*}{$\mathbf{P}$} \\
\hline & \multicolumn{2}{|c|}{ Control group $(\mathrm{n}=\mathbf{3 0})$} & \multicolumn{2}{|c|}{ Study group $(n=30)$} & & \\
\hline & $\mathbf{N}$ & $\%$ & $\mathbf{N}$ & $\%$ & & \\
\hline Cardiogenic shock & 6 & 20.0 & 0 & 0.0 & FE & $0.012 *$ \\
\hline Heart failure & 11 & 36.7 & 3 & 10.0 & $\mathrm{FE}$ & $0.015^{*}$ \\
\hline Arrhythmia & 6 & 20.0 & 4 & 13.3 & $\mathrm{FE}$ & 0.365 \\
\hline Bleeding & 3 & 10.0 & 0 & 0.0 & $\mathrm{FE}$ & 0.119 \\
\hline
\end{tabular}

FE: Fisher' Exact test * Significant at level $\mathrm{P}<0.05$. 
Table 10, Shows distribution of studied sample according to acute coronary syndrome complications throughout period of study, the present study showed that low percentages (20.0\%) of control group had cardiogenic shock compared to none patient in the study group with a significant difference where $\mathrm{P}=0.012$. Also more than one third $(36.7 \%)$ of control group had heart failure compared to $(10.0 \%)$ of patient in study group with a significant difference between two groups where $\mathrm{p}=0.015$. Otherwise, it was observed that minority $(20.0 \%$ and $10.0 \%$ respectively) of control group had arrhythmia and bleeding compared to $13.3 \%$ and $0.00 \%$ in study group with none significant difference was observed between two groups where $\mathrm{P}=0.365$ and 0.119 respectively.

Table 11. Distribution of studied sample according to acute coronary syndrome outcome throughout period of study.

\begin{tabular}{|c|c|c|c|c|c|}
\hline \multirow{3}{*}{ Characteristics } & \multicolumn{4}{|c|}{ The studied sample $(\mathrm{n}=60)$} & \multirow{3}{*}{$\begin{array}{l}\chi^{2} \\
P\end{array}$} \\
\hline & \multicolumn{2}{|c|}{ Control group $(n=30)$} & \multicolumn{2}{|c|}{ Study group $(n=30)$} & \\
\hline & $\mathbf{N}$ & $\%$ & $\mathbf{N}$ & $\%$ & \\
\hline \multicolumn{6}{|c|}{ Duration of stay in ICU } \\
\hline 5 days & 3 & 10.0 & 0 & 0.0 & $\mathrm{FE}$ \\
\hline 4 days & 27 & 90.0 & 30 & 100.0 & 0.075 \\
\hline $\begin{array}{l}\text { Status of patient on } \\
\text { referred }\end{array}$ & 26 & 86.7 & 29 & 96.7 & 3.164 \\
\hline complete recovery & 1 & 3.3 & 1 & 3.3 & 0.206 \\
\hline died & 3 & 10.0 & 0 & 0.0 & \\
\hline
\end{tabular}

Table 11, Shows distribution of studied sample according to acute coronary syndrome outcome throughout period of study, concerning duration of stay in ICU, all (100.0\%) of patients in study group had shorter duration of stay in ICU (4) days compared to $(90.0 \%)$ of patients in control group. Moreover, insignificant difference was observed between control and study group regarding duration of stay in ICU with $\mathrm{P}=0.075$. In relation to status of patient on discharge, it was found that the majority $(86.7 \%)$ of patients in study group were referred compared to $(96.7 \%)$ of patients in control group. Also it is also observed that $10.0 \%$ of patient in control group were died on the $4^{\text {th }}$ day of study compared to nothing in study group.

Table 12. Distribution of studied sample according to total anxiety levels throughout period of study.

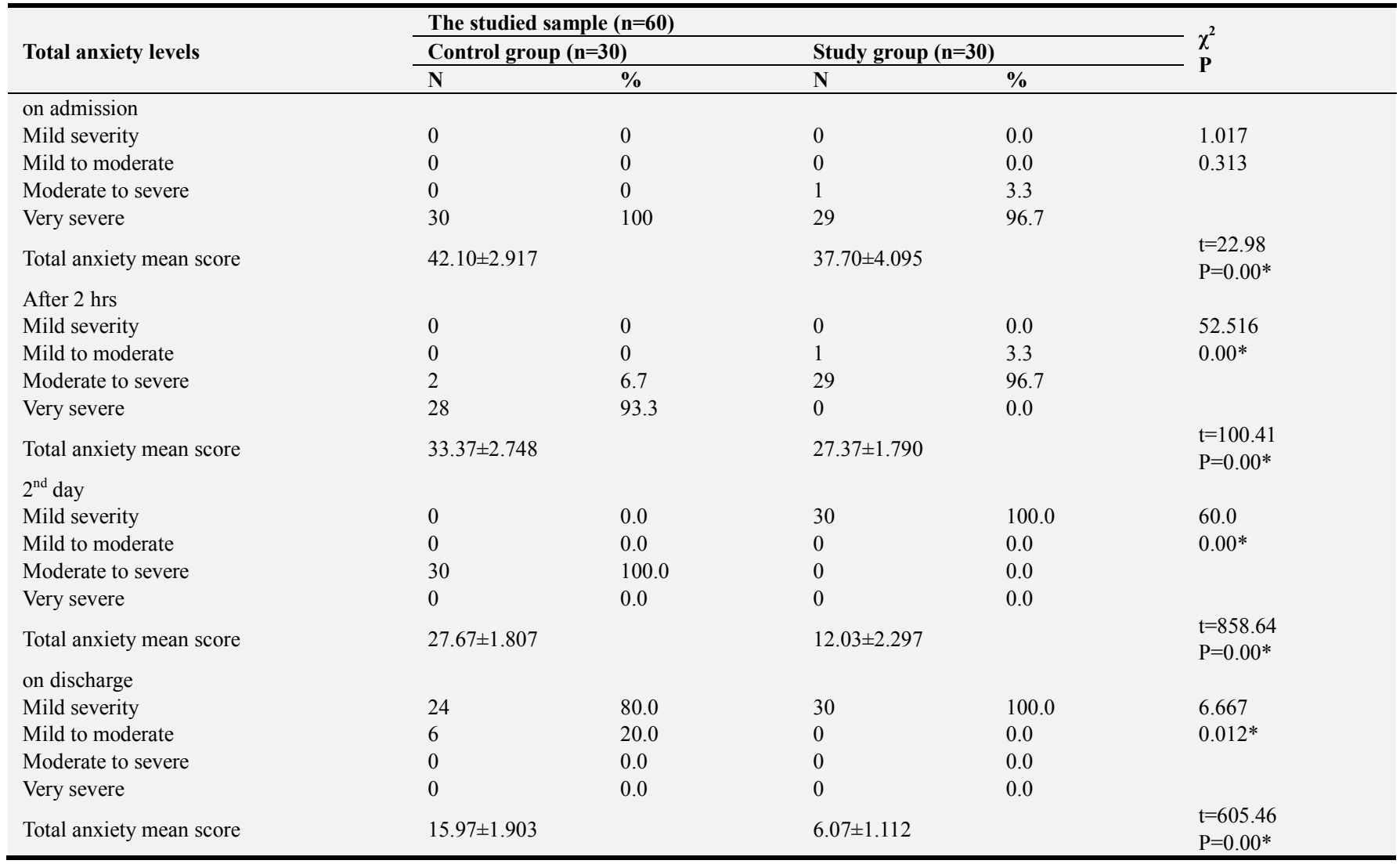

* Significant at level $\mathrm{P}<0.05$.

Table 12, showed distribution of studied sample according to total anxiety scores throughout period of study, it was 
observed that the mean of Hamilton Anxiety Score on admission was $(42.10 \pm 2.917)$ for the control group and $(37.70 \pm 4.095)$ for the study group with significance difference between the two groups with $\mathrm{P}=0.00$. On the other hand, the mean value of Hamilton Anxiety score was significantly reduced to $(6.07 \pm 1.112)$ for the patients managed by the clinical pathway (CP group) and $(15.97 \pm 1.903)$ for the non-CP group on discharge. Also it was noticed that the level of reduction in the study group was higher than its level in the control group after $2 \mathrm{hrs}$ of admission, on $2^{\text {nd }}$ day and upon discharge.

Table 13. Relation between sociodemographic characteristics and total mean scores of anxiety scale among studied groups.

\begin{tabular}{|c|c|c|c|c|}
\hline \multirow{3}{*}{ Characteristics } & \multicolumn{4}{|c|}{ The studied sample Mean \pm SD } \\
\hline & \multicolumn{2}{|c|}{ Control group } & \multicolumn{2}{|l|}{ Study group } \\
\hline & On admission & On discharge & On admission & On discharge \\
\hline \multicolumn{5}{|l|}{ Sex } \\
\hline Male & $42.74 \pm 3.033$ & $16.17 \pm 1.80$ & $37.23 \pm 4.342$ & $6.36 \pm 1.049$ \\
\hline Female & $40.00 \pm 0.816$ & $15.29 \pm 2.215$ & $39.00 \pm 3.207$ & $3.25 \pm 0.886$ \\
\hline $\mathrm{F}, \mathrm{P}$ & $5.461,0.027^{*}$ & $1.177,0.287$ & $1.103,0.303$ & $7.125,0.013^{*}$ \\
\hline \multicolumn{5}{|l|}{ Marital status } \\
\hline Married & $42.50 \pm 3.417$ & $16.11 \pm 2.139$ & $37.26 \pm 3.928$ & $6.07 \pm 1.072$ \\
\hline Single & $38.00 \pm 0.00$ & $17.00 \pm 0.00$ & - & - \\
\hline Widow & $41.82 \pm 1.662$ & $15.64 \pm 1.567$ & $41.67 \pm 4.041$ & $6.00 \pm 1.732$ \\
\hline $\mathrm{F}, \mathrm{P}$ & $1.228,0.309$ & $0.349,0.709$ & $3.385,0.076$ & $0.015,0.915$ \\
\hline \multicolumn{5}{|l|}{ State on discharge } \\
\hline Referred & $41.70 \pm .1 .987$ & $15.57 \pm 1.779$ & $37.69 \pm 4.167$ & $6.07 \pm 1.132$ \\
\hline Complete recovery & $38.00 \pm 0.00$ & $17.00 \pm 0.00$ & $38.00 \pm 0.00$ & $6.00 \pm 0.00$ \\
\hline $\mathrm{F}, \mathrm{P}$ & $1.475,0.345$ & $2.425,0.108$ & $0.005,0.942$ & $0.004,0.953$ \\
\hline
\end{tabular}

* Significant at level $\mathrm{P}<0.05$.

Table 13, represents relation between Sociodemographic characteristics and total mean scores of anxiety scale among studied groups, regarding relation between sex and total mean score of Hamilton Anxiety, it was noticed that male and female mean score of Hamilton Anxiety on admission was $42.74 \pm 3.033$ and $40.00 \pm 0.816$ for control group and then decreased to $16.17 \pm 1.800$ and $15.29 \pm 2.215$ respectively on discharge. While male and female mean score of Hamilton Anxiety on admission for the study group was $37.23 \pm 4.342$ and $39.00 \pm 3.207$ and decreased to $6.36 \pm 1.049$ and $3.25 \pm 0.886$ respectively on discharge with significant difference where $\mathrm{P}=0.013$. Also it was found that the level of reduction of anxiety level in the female of control and study group was higher than its level in male of both groups on discharge. In relation to marital status, there was no significant relation between marital status and total mean score of Hamilton Anxiety for both groups.

Concerning status of patient on discharge, it was observed that the total mean score of Hamilton Anxiety of referred and complete recovery patient of control group on admission was $(41.70 \pm .1 .987$ and $38.00 \pm .0 .0)$ respectively and this mean decreased to $(15.57 \pm 1.779)$ and $(17.00 \pm 0.00)$ respectively on discharge. However the total mean score of Hamilton Anxiety of referred and complete recovery patient in study group on admission was (37.69 \pm 4.167 and $38.00 \pm 0.00$ respectively and this mean decreased to $(6.07 \pm 1.132)$ and $6.00 \pm 0.00$ respectively on discharge.

Table 14. Clinical pathway (CP) evaluation among jury.

\begin{tabular}{llllll}
\hline \multirow{2}{*}{ Clinical pathway $(\mathbf{C P})$ criteria } & \multicolumn{5}{l}{ Number of jury $(\mathbf{n = 1 0})$} \\
\cline { 2 - 5 } & \multicolumn{3}{c}{ Disagree } & Agree \\
\cline { 2 - 5 } & $\mathbf{\%}$ & $\mathbf{N}$ & $\mathbf{\%}$ & $\mathbf{N}$ \\
\hline CP associated with relevant time line & 0.0 & 0 & 100.0 & 10 \\
CP developed by interdisciplinary teams & 0.0 & 0 & 100.0 & 10 \\
\hline
\end{tabular}

\begin{tabular}{llllll}
\hline \multirow{3}{*}{ Clinical pathway (CP) criteria } & \multicolumn{4}{l}{ Number of jury (n=10) } \\
\cline { 2 - 5 } & \multicolumn{4}{l}{ Disagree } & Agree \\
\cline { 2 - 5 } & $\mathbf{\%}$ & $\mathbf{N}$ & $\mathbf{\%}$ & $\mathbf{N}$ \\
\hline CP content based on evidence & 0.0 & 0 & 100.0 & 10 \\
CP meeting all aspect of patient needs & 0.0 & 0 & 100.0 & 10 \\
CP contains key outcomes to be achieved & 0.0 & 0 & 100.0 & 10 \\
CP involved discharge plan & 0.0 & 0 & 100.0 & 10 \\
CP is diagnosis specific & 0.0 & 0 & 100.0 & 10 \\
Variance data is recorded on the CP & 0.0 & 0 & 100.0 & 10 \\
Clarity of CP contents \& management & 0.0 & 0 & 100.0 & 10 \\
procedures & 0.0 & 0 & 100.0 & 10 \\
CP can applied in current CCU & 0.0 & 0 & 100.0 & 10 \\
CP is editorially by independent profession & & & \\
\& has external reviewed. & & & & \\
\hline
\end{tabular}

Table 14, Demonstrates clinical pathway audit evaluation criteria, these results were collected before its implementation for the study group. It was revised by 10 experts in the field of critical care nursing and cardiology medicine. It was noticed that $(100 \%)$ of the audits agreed with all criteria of the established acute coronary syndrome clinical pathway.

\section{Discussion}

Acute coronary syndrome (ACS) is one of the most common causes of intensive care unit (ICU) admission and mortality in both developed and developing countries [21, 22]. Healthcare is undergoing a great change at a rapid rate and clinical pathways are one of the most popular tool that has recently been developed to address and manage many diseases [15]. This study aimed to evaluate the effect of implementing clinical pathway guidelines on clinical outcomes of the patients with acute coronary syndrome. The researchers implemented clinical pathway guidelines for the management of patients with acute coronary syndrome, and compared the 
outcomes (physiological Parameters, arterial blood gases, chest pain, LOS, status of patient on discharge, intake and output, anxiety level and assessment of acute coronary syndrome complications) of patients managed by the clinical pathway with patients managed by the routine cardiac care.

Regarding biosociodemographic characteristics and clinical data, the finding of the present study revealed that the mean age of patents in control group was $(53.00 \pm 7.83$ years $)$, while it was (55.47 \pm 7.49 years) in study group with none significant difference was observed between them. This finding was in line with Keddeas et al (2017) [23] in study about predicting acute coronary occlusion, they mentioned that the mean age of the studied patients was $56.3 \pm 9.66$ years. Also, the present study showed that the majority of the patients in both groups were male and married. These findings were in accordance with Gomar et al (2016) [5], who stated that the prevalence of myocardial infarction was higher in men compared with women in the two groups. Also, Hadi et al (2011) [24] reported that widowed women was high risk for cardiovascular disease and higher inhospital. Concerning level of education, more than one third of the control and study group had university education. This result was similar to Bi et al (2009) [25] they concluded that nearly $60 \%$ of patients had a higher education.

Regarding diagnosis, more than two third of the control and study group diagnosed as STEMI. In this regard Abdelmoneim et al (2014) [26] reported that both the ST segment elevation myocardial infarction and unstable angina, groups had a similar percentage. However, Bi et al (2009) [25] showed that the majority of patients in their study had final diagnosis of STEMI $45 \%$ and NSTEMI $12 \%$.

Concerning medical history, the finding of the present study revealed that the most prevalent risk factor in control and study group was family history of CAD following by smoking history, hyperlipidemia, diabetes mellitus and hypertension. This result was consistent with Abdelmoneim et al (2014) [26] emphasized that the most risk factor for cardiac disease was smoking, following by diabetes, dyslipidemia, and family history of CAD. Similarly, Shaheen et al (2012) [27] concluded that diabetic patients had the highest percentage among patients with ACS following by smokers with positive family history of ACS, and hypertension.

Concerning Lipid profile and cardiac enzymes, the present study revealed increased mean score of cholesterol, LDL level and CK-MB and decreased HDL level for both groups with no significant difference was found between them. The rational for these findings may be due to myocardial tissue necrosis is associated with increased levels of CPK, LDL and troponin due to myocardial cellular damage. This result was agree with Kumar (2012) [28] and Antman (2004) [29] they reported that cardiac enzymes used for assessment and detection of myocardial infarction in the setting of acute coronary syndromes. Also Kumar and Sathian (2013) [30] showed that decreased of levels of HDL and increased level of LDL than the recommended level is a high risk factor for the development of cardiac event.
Regarding Troponin level, the present study showed that, nearly one third of both group had positive troponin level. In this regard Peppes et al (2008) [31] stated that cardiac troponin is the gold standard in the diagnosis of acute coronary syndrome and is measured in all patients with symptoms suggestive of acute coronary syndrome, in conjunction with physical examination and ECG. On the other hand, Antman (2008) [29] and Apple (2010) [32] reported that some patients with myocardial infarction in his study did not have elevated troponins or CK values and they may die before the cardiac markers reach the threshold.

Concerning electrolytes and blood glucose level, the present finding revealed a decreased in serum potassium $(\mathrm{K})$ level but within normal level with no significant difference was found between two groups regarding serum potassium $(\mathrm{K})$ and sodium $(\mathrm{Na})$. This may be justified to that decreasing $\mathrm{K}$ level lead to vasoconstriction and may always associated with the occurrence of acute coronary syndrome [33]. This result was in line with Madias (2000) [34] and Foo (2003) [35] who suggested that reducing serum potassium $(\mathrm{K})$ was detected in patients with acute coronary syndrome. Also Biyani et al (2016) [36] concluded that hyponatremia and hypokalemia are common in patients with acute myocardial infarction. Also the current finding showed that increased of random blood sugar in control group than study group. This may be attributed that more than half of control group in this study had diabetes mellitus and the hyperglycemia may be a stress response to acute illness. This finding was agreement with Samiullah (2010) [37] and Benamer (2015) [38] who reported that hyperglycemia is a common finding associated in patients with acute coronary syndrome.

Concerning physiological parameters (vital signs), the findings of the present study revealed that increased mean score of body temperature, pulse and respiration on admission in both groups and decreased on discharge. The increased of body temperature may be attributed to inflammatory reaction associated with acute coronary syndrome. Similarly Schwartz et al (2001) [39] mentioned that elevated body temperature may be indicators of the inflammatory reaction following myocardial necrosis. Furthermore, the present result showed that a significant improvement in the mean scores of body temperature, Pulse and respiration rate among study than control group from admission to discharge. This improvement may be due to that the subjects in CP group were managed by the clinical pathway where it include frequent observation of patients and allow to detect and manage any abnormalities as soon as possible. This result was agree with Atibioke (2015) [40] who concluded that frequent physical examination of the patients' hemodynamic status such as blood pressure, pulse, respiration and temperature is very important for cardiac patients to detect any sign of complications such pulmonary edema and cardiogenic shock. On the other hand wasserfallen et al (2004) [1] in study about impact of medical practice guidelines on the assessment of patients with acute coronary syndrome mentioned that vital signs and maximal intensity of chest pain did not change significantly after 
implementation of the guidelines.

In relation to blood pressure, the current study presented that there was a significant decreased in mean scores of systolic and diastolic blood pressure of control and study group throughout period of study; on admission, 2nd day and on discharge, but these changes was within the normal ranges of physiological variables. This finding was in line with Tawfeek et al (2016) [8] they showed that a significant decreased mean of systolic (SBP) and diastolic blood pressure in the control group when compared to the study group.

As regard mean arterial pressure (MAP), there was a significant decrease of mean arterial pressure (MAP) among control group compared with study group on admission, after $2 \mathrm{hrs}$ and on discharge. Similarly, Tawfeek et al (2016) [8] found that a significant decreasing of mean arterial pressure (MAP) in the control group compared to study group.

Concerning mean score of central venous pressure (CVP) and oxygen saturation $\left(\mathrm{O}_{2}\right.$ Sat $)$ there was significant increased mean score of central venous pressure among control group compared to study group on admission, after 2 hrs and on $2^{\text {nd }}$ day of admission. This could be attributed to that patients with circulatory insufficiency or shock after acute myocardial infarction may had elevated control CVP. This result was contrast with Kumar (2004) [41] and Mich and (2003) [42], they documented that there was no significant correlation between increasing of CVP and changes in right ventricular volume and cardiac performance. Also the current study showed an improvement of mean score of oxygen saturation $\left(\mathrm{O}_{2}\right.$ Sat) among control and study group on $2^{\text {nd }}$ day of admission and discharge. In this regard Nikolaoua et al (2015) [43] showed that acute coronary syndrome need adequate oxygenation until the arterial oxygen saturation can be measured reliably.

In relation to third and fourth heart sound (S3, S4), the present finding revealed that less than one quarter and more than one third of the control group had audible S3 and S4 through period of the study, while in study group the S3 and S4 heart sound was not found throughout the period of study. This could be attributed to that third heart sound (S3) during acute myocardial infarction suggests a large infarction. In this regard, Patel R et al (2009) [44] they noticed that the coronary heart disease without LV dysfunction does not produce an S3. However, if coronary heart diseases results in left ventricular dysfunction either acute or chronic leading to a poor ejection fraction. In addition Johnston et al (2007) [45] reported that S4 may be detected in the early phases of acute ischemia and acute myocardial infarction.

As regard alterations in respiratory sounds throughout period of study, the present study showed that low percentage of the control group had audible crackles, wheezing and persistence cough after $2^{\text {nd }}$ day of admission, while in the study group, the crackles and wheezing sound and persistence cough was not present after $2^{\text {nd }}$ day of admission. This may be due to that some patient of control group had heart failure. In this respect Mooe and Stenfors (2015) [46] revealed that ACS was associated with higher risk of heart failure manifested by wheezing, crackles, and persistence cough.

Concerning chest pain, the current finding showed that all the patients of both groups had chest pain on admission and this percentage decreased in study groups than control groups. However there was improvement in study group than control group on $2^{\text {nd }}$ day of admission and discharge. The same finding was indicated by Wasserfallen et al (2004) [1].

In relation to arterial blood gases, the present study documented that the mean value of $\mathrm{PH}$ was improved from admission to discharge in the $\mathrm{CP}$ group while it was declined in control group from normal acidity on admission to metabolic acidosis on discharge. This finding point out the necessity of careful assessment of patient and processes of care. This result was agreement with Gandh and Akholkar (2015) [47] who concluded that metabolic acidosis may occur in the early stages of an acute myocardial infarction. Similarly Nagai et al (2010) [48] reported that systemic acidosis was noticed in (34\%) of patients with STEMI. In relation to the mean value of $\mathrm{PaCO}_{2}$, the value was declined on the both groups from normal acidity to acidosis from admission to discharge. Also the mean value of $\mathrm{PaO}_{2}$ was improved among patients in the $\mathrm{CP}$ and control groups from admission to discharge. This result was congruent with AbdElwanees et al (2014) [18] they documented that the mean value of $\mathrm{PaCO}_{2}$ among the study and control groups was decreased on the both groups from respiratory acidosis to normal acidity. Also the mean value of $\mathrm{PaO}_{2}$ was relatively improved among patients in the $\mathrm{CP}$ and non- $\mathrm{CP}$ groups from admission to discharge.

Regarding acute coronary syndrome complications, The $\mathrm{CP}$ group had low percentages of complications compared to the control group. This result was similar with Ban et al (2012) [49] who reported that the group who managed by clinical pathway had less number of complications compared to the non-CP group. Also Doevendans (2004) [50] and Hillis (2005) [51] found that cardiogenic shock occurs in 5-20\% of patients following myocardial infarction.

Concerning duration of stay in ICU, the current result showed that no significant difference was observed between control and study group regarding duration of stay in ICU. However CP group stay 4 days in ICU compared to 5 days in none CP. These shorter durations of ICU stay may be attributed to the effect of using the developed clinical pathway that optimizing patient care and timing interventions. This result was in line with Cheah (2000) [15] who reported that patient who had urethral obstruction and managed by clinical pathway had short length of stay (5 days). Conversely, Roberts et al (2004) [52] in study regarding implementing a care pathway for femoral neck fracture in older people reported that there was no benefit of implementing clinical pathway guidelines regarding length of hospital stay and total costs.

In relation to status of patient on discharge, the present finding revealed that the majority of patients in study and control group were referred and only three patients in control group were died on the 4 th day of study compared to nothing 
in the study group. This result was agreed with Barbieri et al (2009) [53] who documented that the rate of patients discharged to home didn't increase by the use of clinical pathways in patients with joint replacement. On the other hand a study conducted by Kwan et al (2005) [54] regarding implementing clinical pathway guidliens for stroke patients, they found that CPs didn't provide any significant additional benefit over standard medical care in terms of clinical outcomes (death or discharge destination).

Concerning Hamilton Anxiety Score, the current finding found that decreasing of the mean Hamilton Anxiety Score in the CP group than its level in the control group on discharge. The improvement of anxiety level for the CP group may be due to the application of the clinical pathway which included psychological care and educational aspects concerning anxiety experience. This finding was supported by Abd-Elwanees et al (2014) [18] who reported that the level of reduction of Hamilton Anxiety Score was higher among patients managed by the clinical pathway than its level in the non-CP group on discharge. Similarly Arora et al (2010) [55] indicated that the state and trait anxiety of myocardial infarction patients at baseline differs from discharge and on follow-up.

Regarding relation between sex and total mean score of Hamilton Anxiety, the present result revealed that the level of reduction of total mean score of Hamilton Anxiety in the female patients in control and study group was higher than its level in male on discharge. This may be due to that the male patient had high level of anxiety since they had more responsibilities in the life and had apprehensions about the recovery of illness. This finding was in contrast with Easton et al (2016) [56] they stated that the female patients are more anxious than males. In addition, the present study found insignificant relation between marital status and total mean score of Hamilton Anxiety for both groups. In contrast, Molloy et al (2009) [57] reported that all unmarried men and women were significantly more likely to experience psychological distress than married patients.

Concerning relation between status of patient on discharge and total mean score of Hamilton Anxiety, the present finding showed that the total mean score of Hamilton Anxiety of referred patients and complete recovery among $\mathrm{CP}$ group was decline than its level in control group on discharge. This may be due to that clinical pathway guidelines include discharge plan that provide a continuous care and help patients to cope with their disease. This finding was supported by Psychiat (2014) [58] who found that discharge plan helps to provide a continuous care with the least amount of stress for patients. Similarly Cebeci and Çelik (2011) [59] their findings suggested that the stress and anxiety of the intervention group on discharge decreased significantly compared with those of the control group. Moreover Astin et al (2005) [60] added that nurses usually do not mention essential issues about treatment because of workload and forgetfulness, or they might be reminded at the very last moments of the patients' discharge which hardly ever provide the continuance of the care. Therefore, their discharge issue should be revised.
Regarding Clinical pathway evaluation by panel of experts, the present result found that all panel of experts agreed with all established acute coronary syndrome clinical pathway criteria. This result was agree with Abd-Elwanees et al (2014) [18] they stated that all the audits agreed with all criteria of the established AECOPD clinical pathway except one criteria and they were strongly agreeing its application in clinical practice.

\section{Conclusion}

It can be concluded that patients with ACS who managed by using a clinical pathway had a significant improvement in the mean scores of body temperature, pulse and respiration rate than control group from admission to discharge. Also the present study documented that the mean value of $\mathrm{PH}$ was improved from admission to discharge in the CP group. The CP group had low percentages of complications compared to the control group. This study also showed that that no significant difference was observed between control and study group regarding duration of stay in ICU. Also the current study found that decreasing of the mean Hamilton Anxiety Score in the CP group than its level in the control group on discharge.

\section{Recommendations of the Study}

Based on the findings of this study, the following recommendations are suggested;

Clinical pathway should be implemented routinely for patients with acute coronary syndrome. Establishment of cardiac rehabilitation unit attached to the cardiac intensive care unit. Nurses should be encouraged to collaborate with the other health members to provide a comprehensive holistic care for the patients with ACS utilizing the clinical pathway. Integrating ACS clinical pathway into plan of care to replace the traditional nursing care plan. Replication of study on a larger sample selected from different geographical area in Egypt. Implementing a clinical pathway must be included in nursing curriculum to enhance student nurse's knowledge.

\section{Limitations of the Study}

The study is confined to one geographical area at Tanta which limited the study generalization.

\section{References}

[1] Wasserfallen J, Berger A, Eckert P, and Yersin B. Impact of medical practice guidelines on the assessment of patients with acute coronary syndrome without persistent ST segment elevation. International Journal for Quality in Health Care, 2004; 16(5): 1-7.

[2] Fox KA, Goodman SG and Klein W. Management of acute coronary syndromes. Variations in practice and outcome. Findings from the Global Registry of Acute Coronary Events. Eur Heart J, 2002; 23: 1177-89. 
[3] Jarvis S and Saman S. Diagnosis, management and nursing care in acute coronary syndrome. Nursing Times, 2017; 113(3): 31-35.

[4] Go AS, Mozaffarian D, Roger VL. Heart disease and stroke statistics - 2013 update: A report from the American Heart Association. Circulation 2013; 127(6):245-250.

[5] Gomar F, QuilisC, Leischik R, Lucia1A. Epidemiology of coronary heart disease and acute coronary syndrome. Ann Transl Med, 2016; 4(13):256-270.

[6] Youssef G, Kassem H, Ameen O, Al Taaban H and Rizk H. Pre-hospital and hospital delay in patients with non-ST elevation acute coronary syndromes in tertiary care. The Egyptian Heart Journal, 2017; 69(3):177-181.

[7] Andrikopoulos G, Tzeis S, Mantas I, et al. Epidemiological characteristics and in-hospital management of acute coronary syndrome patients in Greece: results from the TARGET study. Hellenic J Cardiol. 2012;53(1):33-40.

[8] Tawfeek H, Nour M, Bary A, Fattah A. Contemporary retrospective analysis of acute coronary syndrome. An Egyptian study. The Egyptian Journal of Critical Care Medicine, 2016; 4(1):79-84.

[9] Sadaka M, El-Sharkawy E, Sobhy M and Hammad B. Longterm prognostic implication of coronary plaque characterization as detected by 64-multidetector computed tomography in Egyptian population. The Egyptian Heart Journal. 2017; 69:63-70.

[10] Abdel Rahman H, Ghany M and Youssef A. Correlation of fragmented QRS complexes with the severity of CAD (using Syntax score) in patients with non-ST elevation acute coronary syndromes. The Egyptian Heart Journal. 2016; 68(2): 125-29.

[11] Smith J, Negrelli J, Megha B, Hawes E, Pharm D and Anthony J. Diagnosis and Management of Acute Coronary Syndrome: An Evidence-Based Update. Diagnosis and Management of Acute Coronary Syndrome. American Board Family Medicine J, 2015; 28(2): 283-93.

[12] Ferry C, Fitzpatrick M, Long P, Levi C and Bishop R. Towards a Safer Culture: clinical pathways in acute coronary syndromes and stroke. Medical J of Australia, 2004; 180: 92-96.

[13] Herck P, Vanhaecht K and W Sermeus. Effects of clinical pathways: do they work? Journal of integrated clinical pathways, 2004; 8(1): 95-105.

[14] Li1 W, Liu1 K, Yang1 H and Yu2 C. Integrated clinical pathway management for medical quality improvement based on a semiotically inspired systems architecture. European Journal of Information Systems, 2014; 23, 400-417.

[15] Cheah J. Clinical Pathways - An Evaluation of its Impact on the Quality of Care in an Acute Care General Hospital in Singapore. Singapore Med J, 2000; 41(7): 335-346.

[16] Rotter T, Kinsman L, James EL, Machotta A, Gothe H, Willis J, Snow P and Kugler J. Clinical pathways: effects on professional practice, patient outcomes, length of stay and hospital costs. Cochrane Collaboration and published in The Cochrane Library. Published by John Wiley \& Sons, Ltd. 2010, Issue 7.

[17] Shields A. Pathways to Improving Patient Safety and Reduced Cost: The Implementation of Clinical Effectiveness Guidelines for Congenital Cardiac Anomalies, Critical Care
Nurse J, 2013; 33( 4,):79-82.

[18] Abd-Elwanees A, El-Soussi A, Othman S, Ali R. Effect of Implementing Clinical Pathway on the Clinical Outcomes of Patients with Acute Exacerbations of Chronic Obstructive Pulmonary Disease. International Journal of Nursing Science, 2014; 4(1): 1-10.

[19] Hamilton M. The assessment of anxiety states by rating. Br J Med Psychol,1959; 32:50-55.

[20] Maier W, Buller R, Philipp M, \& Heuser I. The Hamilton Anxiety Scale: Reliability, Validity and Sensitivity to Change in Anxiety and Depressive Disorders, J Affect Disorder, 1988; 14(1) 61-8.

[21] Obaya M, Yehia M, Hamed L and Fattah A. Comparative study between elderly and younger patients with acute coronary syndrome, The Egyptian Journal of Critical Care Medicine, 2015; 3(1):69-75

[22] Sadaka M, El-Sharkawy E, Sobhy M and Hammad B. Longterm prognostic implication of coronary plaque characterization as detected by 64-multidetector computed tomography in Egyptian population. The Egyptian Heart Journal, 2017; 699(1): 63-70.

[23] Keddeas V, Swelim S and Selim G. Role of 2D speckle tracking echocardiography in predicting acute coronary occlusion in patients with non ST-segment elevation myocardial infarction, The Egyptian Heart Journal, 2017;69(2): 103-110.

[24] Hadi AR, Ahmed H, Wael A, Jawad A, and Jassem A. Marital Status and Outcome of Patients Presenting with Acute Coronary Syndrome: An Observational Report. Clin. Cardiol J, 2011; 35(12):741-8.

[25] Bi Y, Gao R, Patel A, Su S, Gao W, Hu D, Huang D, Kong L, Qi W, Wu Y, Yang Y and Turnbull F. Evidence-based medication use among Chinese patients with acute coronary syndromes at the time of hospital discharge and 1 year after hospitalization: Results from the Clinical Pathways for Acute Coronary Syndromes in China (CPACS) study. Am Heart J, 2009;157(3):509-16.

[26] Abdelmoneim H, Ali H and Abdulkader S. Demographics of Acute Coronary Syndrome (ACS) Egyptian patients admitted to Assiut University Hospital: Validation of TIMI and GRACE scores. The Egyptian Journal of Critical Care Medicine, 2014;2(1):3-11.

[27] Shaheen S, Magdi A, Esmat I, Mohannad A, and EL Kilany W. National Heart Institute Acute Coronary Syndrome Registry. Med. J. Cairo Univ, 2012; 80( 2): 141-149.

[28] Kumar A, Sathian B. The clinical utility of lipid profile and positive troponin in predicting future cardiac events. Asian Pac J Trop Dis, 2012;2(1):66-69.

[29] Antman EM, Hand M, Armstrong PW, Bates ER, Green LA, Halasyamani LK. update of the ACC/AHA 2004 guidelines for the management of patients with ST-elevation myocardial infarction: a report of the American college cardiology/American heart association task force on practice guidelines. Am Coll Cardiol, 2008;51(1):210-47.

[30] Kumar A and Sathian B. Correlation between lipid profile and troponin I test results in patients with chest pain in Nepal, Asian Pac J Trop Biomed, 2013; 3(6): 487-491. 
[31] Peppes V, Rammos G, Manios E, Koroboki E, Rokas S, and Zakopoulos N. Correlation between myocardial enzyme serum levels and markers of inflammation with severity of coronary artery disease and Gensini score: A hospital-based, prospective study in Greek patients. Clin Interv Aging J. 2008; 3(4): 699-710.

[32] Apple S. High-sensitivity cardiac troponin assays: what analytical and clinical issues need to be addressed before introduction into clinical practice. Clin Chem J,2010; 56(6):886-91.

[33] Sekiyama H, Nagoshi T, Komukai K, Matsushima M and Katoh D. Transient decrease in serum potassium level during ischemic attack of acute coronary syndrome: Paradoxical contribution of plasma glucose level and glycohemoglobin. Cardiovasc Diabetol J. 2013; 12(1): 4.

[34] Madias JE, Shah B, Chintalapally G, Chalavarya G and Madias NE. Admission serum potassium in patients with acute myocardial infarction: its correlates and value as a determinant of in-hospital outcome. Chest J. 2000;118(4):904-913.

[35] Foo K, Sekhri N, Deaner A, Knight C, Suliman A, Ranjadayalan K and Timmis AD. Effect of diabetes on serum potassium concentrations in acute coronary syndromes. Heart J. 2003;89(1):31-35.

[36] Biyani S, Lodha R and ZLal R. Study of Serum Electrolytes and Blood Urea Levels with Cardiac Markers in Acute Myocardial Infarction. Sch. J. App. Med. Sci J, 2016; 4(5):1570-1573

[37] Samiullah S, Qasim R, Imran S and Mukhtair J. Frequency of stress hyperglycaemia and its influence on the outcome of patients with spontaneous intracerebral haemorrhage. J Pak Med Assoc, 2010;60(1):660-3.

[38] Eljazwi I, Mohamed R, Masoud H, Tuwati M, and Elbarsha A. Association of Hyperglycemia with In-Hospital Mortality and Morbidity in Libyan Patients with Diabetes and Acute Coronary Syndromes. Oman Med J. 2015; 30(5): 326-30.

[39] Schwartz DS, Bremner RM, Baker CJ. Regional topical hypothermia of the beating heart preservation of function and tissue. Ann thorac surg, 2001;72(1):804-9.

[40] Atibioke O. Nurses Roles in Assessment of Chest Pain in the Emergency Department (ED), Egina Project Medic J,2015; September 27

[41] Kumar A, Anel R and Bunnell E. Pulmonary artery occlusion pressure and central venous pressure fail to predict ventricular filling volume, cardiac performance, or response to volume infusion in normal subjects. Crit Care Med J,2004;32(3):6919.

[42] Michard F, Alaya S, Zarka V, Bahloul M, Richard C and Teboul JL. Global end diastolic volume as an indicator of cardiac preload in patients with septic shock. Chest $J, 2003$; 124(5):1900-8.

[43] Nikolaoua N, Arntz H, Bellouc A, Beygui F, Bossaert L and Cariouf A. on behalf of the Initial management of acute coronary syndromes section Collaborator. European Resuscitation Council Guidelines for Resuscitation 2015 Section. Initial management of acute coronary syndromes. Resuscitation J, 2015;95 (1):264-277.
[44] Patel R, Bushnell DL and Sobotka PA. Implications of an audible third heart sound in evaluating cardiac function. West J Med, 2009;158(6):606-9.

[45] Johnston M, Collins SP, and Storrow AB. The third heart sound for diagnosis of acute heart failure. Curr heart fail Resp J, 2007;4(3):164-8.

[46] Mooe T, Stenfors N. The Prevalence of COPD in Individuals with Acute Coronary Syndrome: A Spirometry-Based Screening Study. US National Library of Medicine National Institutes of Health, 2015; 12(4):453-61.

[47] Gandh A and Akholkar P. Metabolic acidosis in acute myocardial infarction, Int J Adv Med. 2015; 2(3): 260-63.

[48] Nagai T, Anzai T, Kaneko H and Anzai A. Impact of Systemic Acidosis on the Development of Malignant Ventricular Arrhythmias After Reperfusion Therapy for ST-Elevation Myocardial Infarction. Circulation Journal, 2010;74(1):1808-16.

[49] Ban A, Ismail A, Harun R, Abdul Rahman A, Sulung S, and Mohamed A. Impact of clinical pathway on clinical outcomes in the management of COPD exacerbation, BMC Pulm Med J, 2012; 12(1): 1-27.

[50] Wehrens XH and Doevendans PA. Cardiac rupture complicating myocardial infarction. Int J Cardiol, 2004; 95(2-3):285-92.

[51] Hillis GS, Møller JE, Pellikka PA, Bell MR and Verzosa GC. Prognostic significance of echocardiographically defined mitral regurgitation early after acute myocardial infarction. Am Heart J, 2005; 150:1268-1275.

[52] Roberts HC, Pickering RM, Onslow E, Clancy M, Powell J and Roberts A. The effectiveness of implementing a care pathway for femoral neck fracture in older people: a prospective controlled before and after study. Age Ageing J, 2004; 33(2):178-84.

[53] Barbieri A, Vanhaecht K, Herck P, Sermeus W, Faggiano F, Marchisio S and Panella M. Effects of clinical pathways in the joint replacement a meta-analysis, BMC J, 2009; 7(1): 1-8.

[54] Kwan, J. \& Sandercock, P. In-hospital care pathways for stroke. Stroke, 2005; 36(1): 1348-49.

[55] Arora D,. Anand M, Katyal V. K., and Anand V. Anxiety and Well-being among Acute Coronary Syndrome Patients: Overtime Academy of Applied Psychology J. 2010; 36(1): 79-88.

[56] Easton K, Coventry P, Lovell K, Carter L and Deaton C, Prevalence and Measurement of Anxiety in Samples of Patients With Heart Failure. J Cardiovasc Nurs,2016; 31(4): 367-379.

[57] Molloy G Stamatakis E, Randall G, and Hamer M. Marital status, gender and cardiovascular mortality: Behavioral, psychological distress and metabolic explanations, Soc Sci Med J, 2009; 69(2): 223-8.

[58] Psychiat E. Anxiety in patients with acute coronary syndromes, European Journal of Psychiatry, 2014; 28(3):1-8.

[59] Cebeci F and Çelik SŞ. Effects of discharge teaching and counselling on anxiety and depression level of CABG patients. Turkish J Thorac Cardiovasc Surg, 2011; 19:170-6.

[60] Astin F, Jones K, Thompson DR. Prevalence and patterns of anxiety and depression in patients undergoing elective percutaneous trans luminal coronary angioplasty. Heart Lung J, 2005; 34: 393-401. 